\title{
An Advanced Review of the Relationships between Sahel Precipitation and Climate Indices: A Wavelet Approach
}

\author{
Churchill Okonkwo \\ Beltsville Center for Climate System Observation, Atmospheric Science Program, Howard University, Washington, DC 20059, USA \\ Correspondence should be addressed to Churchill Okonkwo; churchill.okonkwo@bison.howard.edu
}

Received 15 January 2014; Revised 25 March 2014; Accepted 26 March 2014; Published 28 April 2014

Academic Editor: Helena A. Flocas

Copyright (C) 2014 Churchill Okonkwo. This is an open access article distributed under the Creative Commons Attribution License, which permits unrestricted use, distribution, and reproduction in any medium, provided the original work is properly cited.

\begin{abstract}
The interannual and decadal to multidecadal variability of precipitation in western Sahel region was examined using wavelet transform and coherency analysis. The aim was to identify the major climate index that has a robust relationship with Sahel precipitation (drought). The results show that ENSO, North Atlantic Oscillation (NAO), Atlantic Multidecadal Oscillation (AMO), and Indian Ocean Dipole (IOD) all have some relationship with precipitation at different time scales which is in agreement with recent studies. There is an antiphase relationship between Sahel precipitation and ENSO at the 3-4-year band localized around 1982/83 El Niño episode. This indicates a cause and effect relationship between the droughts of 1983 and 1982/83 El Niño. In addition, wavelet transform coherence analysis also revealed a relatively antiphase relationship between AMO and precipitation signifying cause and effect. The wavelet analyses indicate that IOD control on rainfall variability in Sahel is limited to the east $\left(15^{\circ} \mathrm{E}-35^{\circ} \mathrm{E}\right)$. Advancing this understanding of variability in rainfall and climate forcing could improve the accuracy of rainfall forecast.
\end{abstract}

\section{Introduction}

Several authors have reported marked interannual variability in rainfall across Africa [1-3]. Since economic development in the region is highly dependent on water availability [4], the effect of climate variability on rainfall is critical [5]. Western Sahel region (latitudes $14^{\circ} \mathrm{N}$ and $18^{\circ} \mathrm{N}$-longitude $-18^{\circ} \mathrm{W}$ to $10^{\circ} \mathrm{W}$ ) is the semiarid transition zone between the Sahara desert and humid tropical Africa that is prone to drought $[6,7]$. The Disaster Management Center (DMC) [8] reported that more than 900,000 people were severely affected by the devastating drought of the 1970s across the Sahel. The associated social and economic consequence of drought such as failure in crop yield, destruction of pasture, and famine has led to a series of studies exploring the interactions and dynamics that control precipitation within the region.

Over the past three decades, studies on the possible causes of drought in Sahel have focused on forcing by either sea surface temperature (SST) or land-atmosphere interaction. Simulations of hydrological impact of land-atmosphere interactions include [9-12] which all attributed reduced rainfall to degradation of land surface at least in part. $\mathrm{Li}$ et al. [12] confirmed the impact of land surface changes on the regional climate through a feedback mechanism that sustains drought. The contribution of these mechanisms has however been exaggerated $[13,14]$ especially the characterization of desertification in the Sahel as irreversible.

There have also been several studies that examined the teleconnection between rainfall variability in Sahel and variation in SST over the tropical Pacific $[15,16]$. While it has been concluded that SST patterns play a significant role in rainfall variability in West Africa $[17,18]$, there is still a debate regarding the major drivers [19]. Several results found that regional weather patterns forced by North Atlantic Oscillation (NAO) have more influence on the local climate in Sahel region [20-23]. Zhang and Delworth [24] and Delworth et al. [25] have linked the Atlantic Multidecadal Oscillation (AMO) to low frequency variations extending back to the nineteenth century.

In addition to the above teleconnection, the role of the Mediterranean sea as having a strong influence on precipitation across the Sahel has been suggested [26]. On the other hand, the influence of the Indian Ocean Dipole (IOD) on both Sahel rainfall and Indian monsoon has been suggested $[27,28]$. Studies on the role of El Niño-Southern Oscillation (ENSO) and Pacific Ocean in modulating Sahel precipitation 
include those of [29-31]. A strong link between the decaying phase of La Niña and developing phase of El Niño has been established by Joly and Voldoire [32]. The limiting role of ENSO on rainfall variability only on eastern Sahel has also been suggested [33]. One of the conclusions that came out of these multiple studies is that the interannual to decadal variability in precipitation over West Africa is controlled by competing physical mechanisms [34].

Despite these advances on the possible causes and trends of persistent drought in Sahel region, there are still projection uncertainties and consensus that models cannot reliably predict future climates in the region $[17,18,30,34,35]$. This had led to big spreads in projections $[17,36]$.

The spread in projections in this semiarid region with high interseasonal, interannual, and interdecadal variability in rainfall $[22,37,38]$ could lead to some serious repercussions on the local economy, farming, and livestock production. More accurate modeling is therefore not only essential in improving our understanding of circulation across the Sahel region but also crucial in planning for future impact of climate change and variability. Accurate modeling and better projections however depend on use of appropriate climate forcing and understanding of the complex dynamics in play in this region.

The major aim of this advanced review is to identify the major climate index that has a robust relationship with Sahel precipitation (drought) using a wavelet approach. Most of the studies reviewed above have employed either coupled ocean atmosphere general circulation model [24] or dynamical modeling [21]. The specific nature of rainfall time series (variability) and drought outbreaks in the Sahel region makes its analysis with wavelet potentially advantageous. The most important advantage of wavelet analysis is that, unlike classical spectral analysis that requires the restrictive assumption of stationarity, wavelet approach focuses on time series that change with time $[39,40]$. Wavelet analysis is also a better tool for extracting features locally. It achieves this by decomposing patterns while preserving and displaying locational information that makes analysis of dependencies between two signals easier. Finally, wavelet cross coherence analysis between ENSO-and LC level is of high importance with respect to long-term water resources problem. One disadvantage of continuous wavelet approach is the edge effect at the beginning and end of the time series. This makes information within the cone of influence less accurate.

This advanced review differs from previous studies by applying wavelet statistical analysis to climate indices to study how they modulate precipitation in the Sahel region. The datasets and preparation will be described in Section 2. The rainfall characteristics and climatology of the Sahel region are provided in Section Three. Description of the wavelet approach and results will be given in Section 4 together with the difference between rainfall variability in eastern and western Sahel in relation to these climate indices. Section 5 provided summary and conclusions.

\section{Data and Preparation}

2.1. Dataset. There are two primary precipitation datasets used in this study. One is the Global Precipitation Clima- tology Project (GPCP v.2) 2.5-degree global grid monthly estimate of precipitation, which is a combination of merged satellite data (from infrared and microwave imagers) and gauge observations [41]. These observed data are daily data resolved to monthly time steps. The second precipitation dataset used in the study is the gridded station monthly rainfall anomalies $(\mathrm{cm})$ taken from the National Oceanic and Atmospheric Administration (NOAA) and Global Historical Climatology Network (GHCN) [42]. The gridded data points were produced on a $5^{\circ}$-by- $5^{\circ}$ basis and averaging for Sahel region to address inhomogeneity was based on a rotated principal component analysis of African precipitation by Janowiak [42]. Also, stations with at least 20 years of data between 1961 and 1990 period were used. Further detail for the data is described at http://www.ncdc.noaa.gov/tempand-precip/ghcn-gridded-products.php.

In this study, we focused on the North Atlantic Multidecadal Oscillation (AMO), North Atlantic Oscillation index (NAO), the Indian Ocean Dipole (IOD), and the Nino 3.4 indices. These are the most studied climate indices linked to modulation of precipitation in the Sahel region. AMO uses gridded global sea surface temperature (SST) and anomalies from 1856 till present derived from UK Met Office SST data [43].

El Niño-Southern Oscillation (ENSO) is represented in this study by SST data from Niño 3.4 region $\left(5^{\circ} \mathrm{S}-5^{\circ} \mathrm{N} / 120^{\circ}-\right.$ $\left.170^{\circ} \mathrm{W}\right)$. The Niño-3.4 SST period used in this study is based on a new strategy of updating by Climate Prediction Center (CPC) of National Oceanic and Atmospheric Administration (NOAA). In this new approach, multiple centered 30-year base periods are used to calculate anomalies for successive 5 -year periods in the historical record [44]. This has the advantage of defining El Niño and La Niña episodes based by their contemporary climatology while previous classification will mostly remain fixed over historical period. Also, warning from longer-term trends that do not reflect interannual ENSO variability defined by a single fixed 30 -year base period is removed [44].

IOD was first identified by [45] and is an interannual climate pattern across tropical Indian Ocean. Cooler than normal water in tropical eastern Indian Ocean and warmer than normal water in tropical western Indian Ocean characterizes the positive IOD period [45]. The trend is reversed during the negative IOD period.

The NAO is a large-scale mode of natural climate variability that is dominant in winter with important impact across the North Atlantic region [46]. According to Jones et al. (1997) [47], NAO measures the sea level pressure difference between the Azores High and Icelandic Low [48]. Positive NAO is linked with strong westerlies while negative NAO is linked with weakened Atlantic storm track [49].

2.2. Data Preparation. As part of the data preparation we aggregated the monthly climate indices into seasons in order to reduce noise following Brown et al. [50]. We applied area weighted averaging to the GPCP gridded monthly time series. This has the advantage of minimizing the spatial data gaps in a semiarid region. Also, Huffman et al. [51] reported that high mean absolute error for individual grid points can 


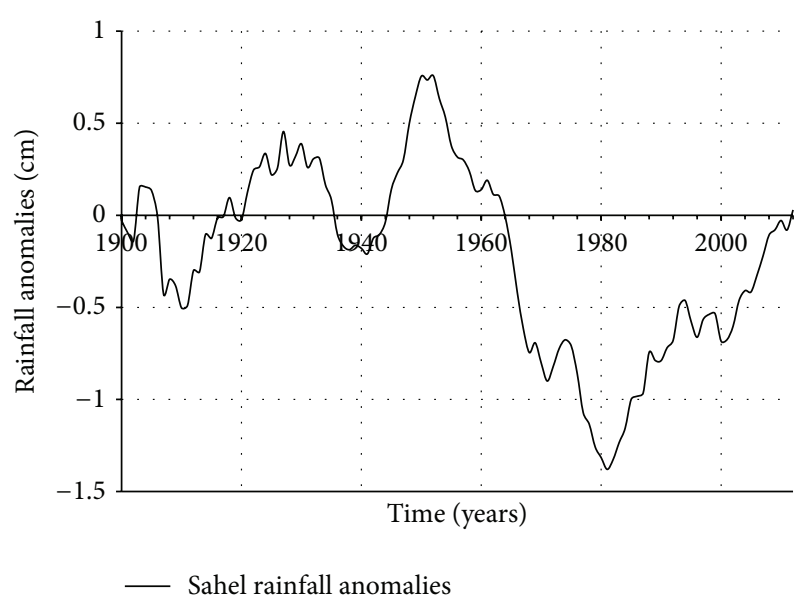

(a)

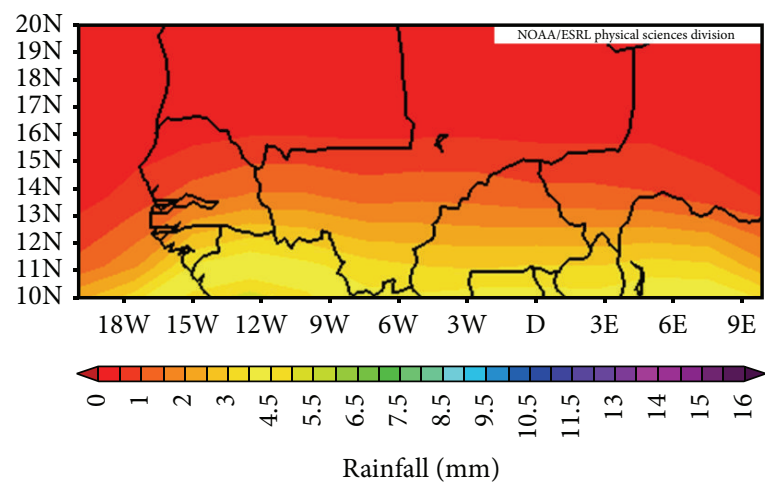

(c)

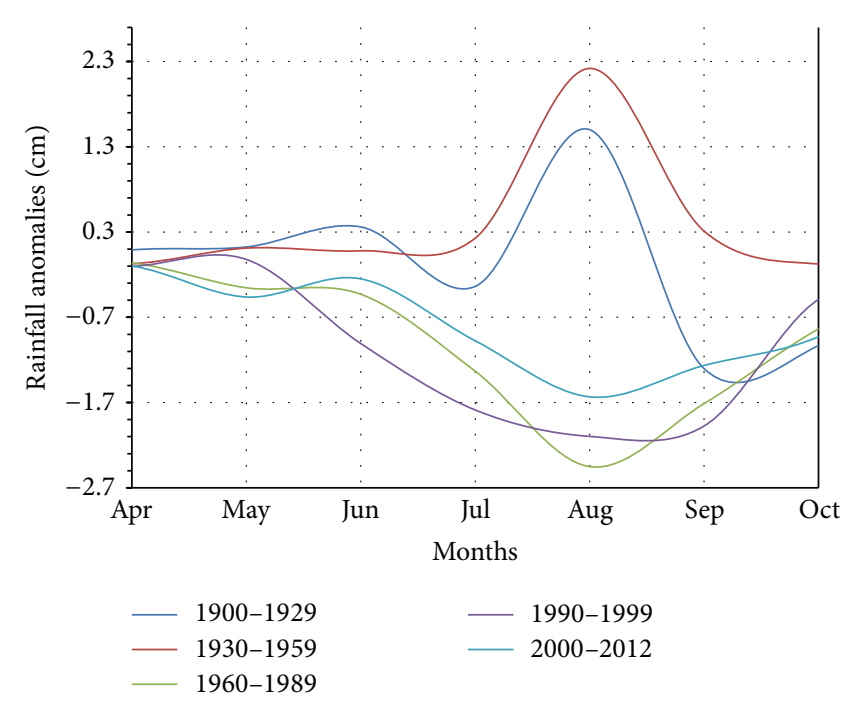

(b)

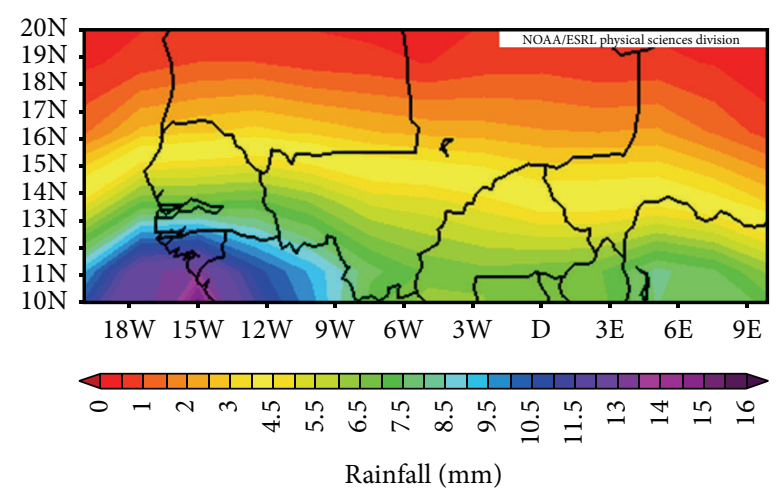

(d)

FIGURE 1: (a) Eight-year running mean of observed Sahel precipitation anomalies (cm). (b) April-October monthly cycle of rainfall anomalies $(\mathrm{cm})$. The rainfall anomalies are relative to 1950-1979. Spatial distribution of western Sahel seasonal precipitation climatology (GPCP) 19812010 for (b) AMJ and (c) JAS.

be minimized by spatial and temporal averaging. We used JAS (July, August, and September) average index correlated with aggregated monthly rainfall totals of JAS corresponding to rainfall peak of raining season in Sahel. The aggregated JAS rainfall allowed us to focus on periods of considerable precipitation, thereby reducing the noise from long periods of dry spells characteristic of this region. The criteria for selecting the GHCN dataset (1900-2012) were based on the suitability for correlation analysis with Atlantic Multidecadal Oscillation (AMO). The climate indices analyzed in this study are mainly archived as a monthly dataset and thus the suitability of GPCP monthly precipitation. The different time frames for climate indices were based on the available time series for each dataset.

There are conflicting definitions of the extent of Sahel region domain in the literature. While there is a consensus on the latitudinal domain $\left(14^{\circ} \mathrm{N}\right.$ to $\left.18^{\circ} \mathrm{N}\right)$, the east-west bounds have varied. Nicholson [52] generally used the $30^{\circ}$ to $35^{\circ} \mathrm{E}$ as the eastern bound while Lamb [53-55] used eastern bound to $10^{\circ} \mathrm{E}$. Some studies have found significant difference in rainfall variability between different sections of Sahel [55].
In this advanced review, we divided the Sahel into east $\left(10^{\circ} \mathrm{E}\right.$ to $\left.35^{\circ} \mathrm{E}\right)$ and west (Atlantic to $\left.10^{\circ} \mathrm{E}\right)$ for the purpose of comparing rainfall variability in relation to these climate indices.

\section{Spatial and Temporal Characterization of Western Sahel Rainfall}

We first characterize the monthly and seasonal (spatial) climatology of rainfall in Sahel region using observational data set. The rainfall time series (Figure 1(a)) in Sahel shows large variability with negative rainfall anomalies since early 1960s. The negative rainfall anomaly of $1.4 \mathrm{~cm}$ around 19831984 corresponds to the period of one of the severe droughts that have plagued the region. This drought condition is characteristic of this region and has been documented by several authors (e.g., [19]). Also of note is the gradual recovery in rainfall (Figure 1(a)) from the year 2000 corresponding to onset of recovery in Sahel rainfall as reported by Nicholson [3]. 


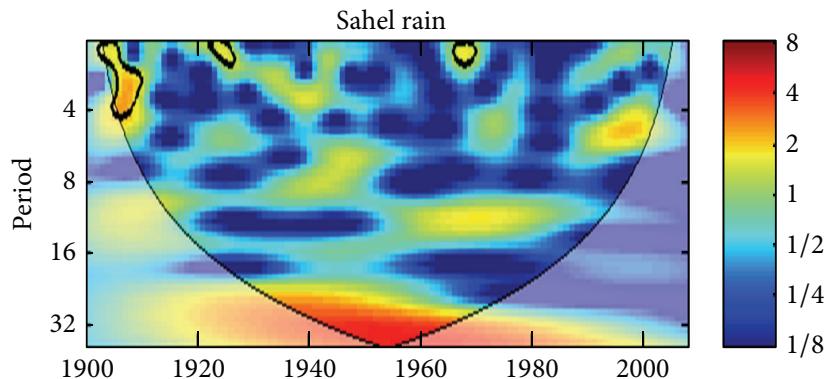

(a)

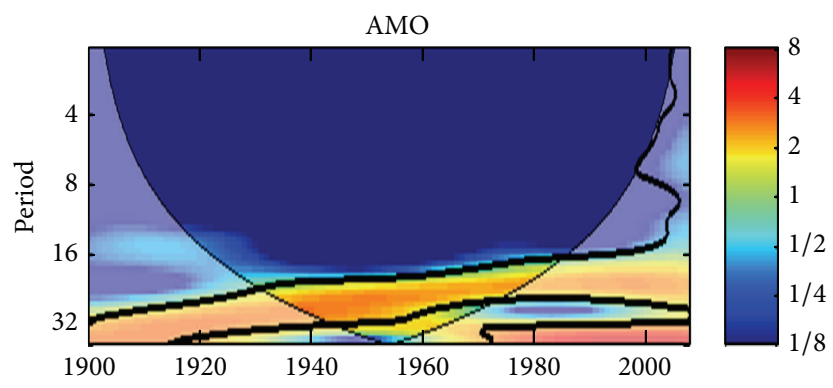

(c)

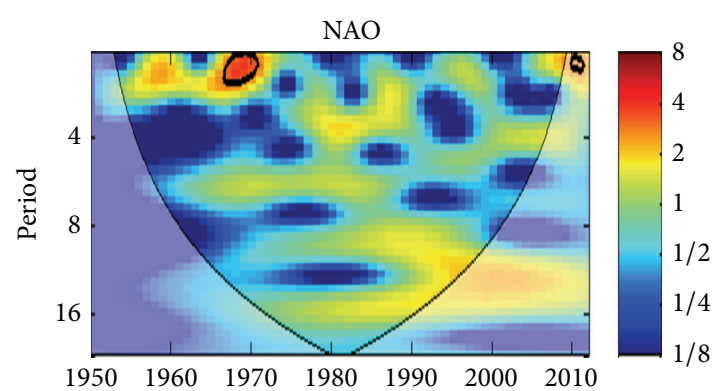

(b)

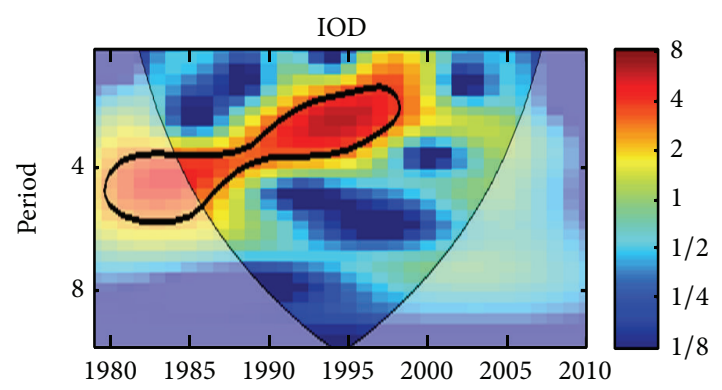

(d)

FIgure 2: Continuous wavelet transform for (a) western Sahel rainfall, (b) North Atlantic Oscillation (NAO), (c) Atlantic Multidecadal Oscillation (AMO), and (d) Indian Ocean Dipole (IOD). The thick contour enclosed regions are greater than $95 \%$ confidence for a red-noise process. The thin solid line indicates the "cone of influence," where edge effects become important.

Figure $1(\mathrm{~b})$ shows the monthly (average) evolution of 1900-2012 April to October western Sahel rainfall $(\mathrm{cm})$ anomalies with respect to 1950-1979. There is short period of rainfall in the region (boreal summer) with maximum rainfall in August. The "wettest" period (1930-1959) has a positive rainfall anomaly of about $2.3 \mathrm{~cm}$ in August. In the 2013 State of the Climate report (Sima et al. 2013) [56], the 2012 extensive flooding in the Sahel was reported as a pointer to a full return to "wet" periods across the region. Our analysis however shows negative rainfall anomalies of $-2.1 \mathrm{~cm}$ and $-1.7 \mathrm{~cm}$ in August for 1990-2000 and 2000-2012 periods, respectively (Figure 1(b)). This difference could be explained by the use of 1981-2010 rainfall climatology in the State of the Climate report, a period characterized by severe drought in Sahel region, whereas our anomaly analysis was based on 1950-1979 rainfall anomaly, a relatively wetter period.

Figure 1(c) (April-June (AMJ)) and Figure 1(d) (JulySeptember (JAS)) show the spatial distribution of seasonal rainfall in the region. Predominantly, heavy rainfall occurs south of latitude $20^{\circ} \mathrm{N}$ while dry conditions are common northwards at the proximity of Sahara desert. Also, east-west uniformity and south-north gradient described by Nicholson (2013) are evident. There is a characteristic rain-band at the southwest region off the coast of Guinea in the JAS seasonal rainfall distribution (Figure 1(d)). The evidence of the limitation of rainfall in this region can also be seen in the difference in the spatial distribution of rainfall between boreal spring (Figure 1(c)) and boreal summer (Figure 1(d)). There is heavier rainfall (between 5.5 and $7.5 \mathrm{~mm} /$ day) in JAS south of latitude $14^{\circ} \mathrm{N}$. Conversely, there is only about $4 \mathrm{~mm} /$ day rainfall for the same latitude band in AMJ.

\section{Wavelet Analysis}

Using wavelet analysis, we examined the interannual variability of precipitation and climate indices by decomposing their (a multiscale nonstationary process) time series into frequency space following the program developed by Torrence and Compo [57]. A summary of the basic theory of continuous wavelet transform (CWT), cross wavelet transform (XWT), and wavelet transform coherency (WTC) following $[57,58]$ is given as

$$
\mathscr{W}(\tau, s)=\frac{1}{(s)^{1 / 2}} \int_{-\infty}^{+\infty} X(t) \psi^{*}\left(\frac{t-\tau}{s}\right) d t,
$$

where $\psi(t)$ is the mother wavelet defined by $\tau$, the transition parameter corresponding to the position of the wavelet, and $s$ is the scale dilation parameter that determines the width of the wavelet. The variability of the dominant mode with time was determined using the Morlet wavelet with a wavenumber $w 0=6$ as the mother wavelet. The choice of Morlet wavelet is based on its localization in time and frequency making it a good tool in extracting features [58]. Information about the periodicity of the time series data can be extracted from the CWT while cross wavelet transform (XWT) helps in determining whether the two time series are statistically significant by Pearson's correlation coefficient. Detailed methodology of wavelet transform can be found in $[57,58]$.

4.1. Continuous Wavelet Transform. Figure 2 shows the CWT of rainfall in the Sahel and the climate indices. The major periodicity can be seen in the power spectrum near the 2- 


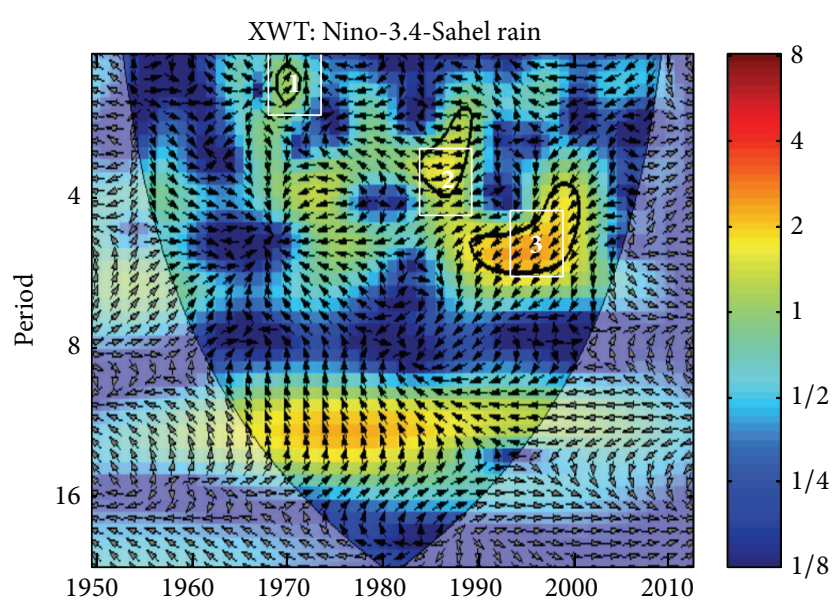

(a)

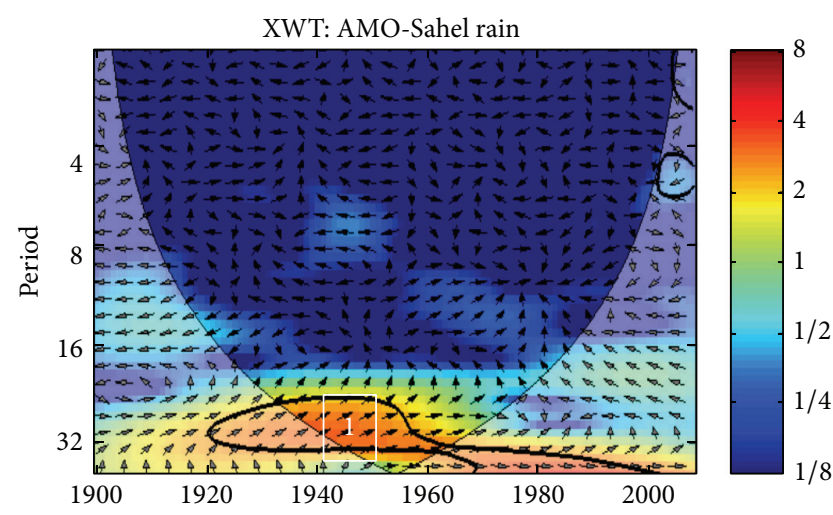

(c)

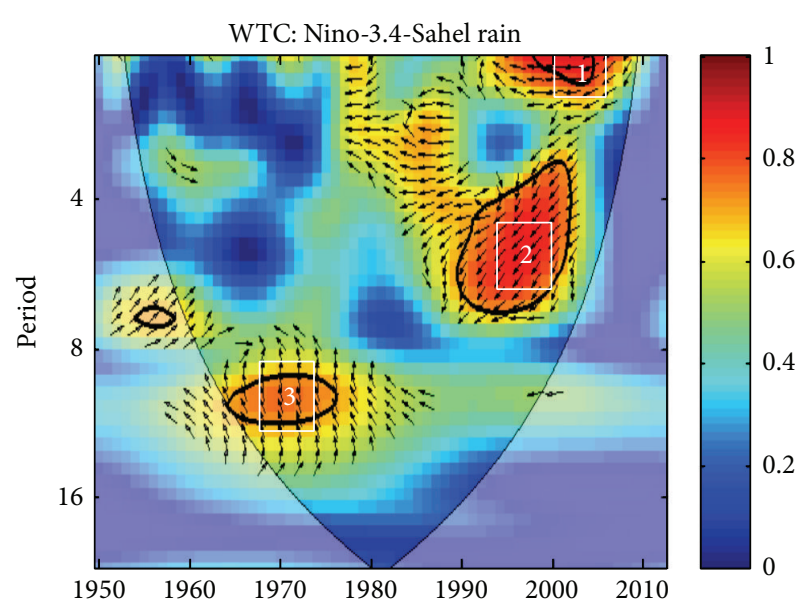

(b)

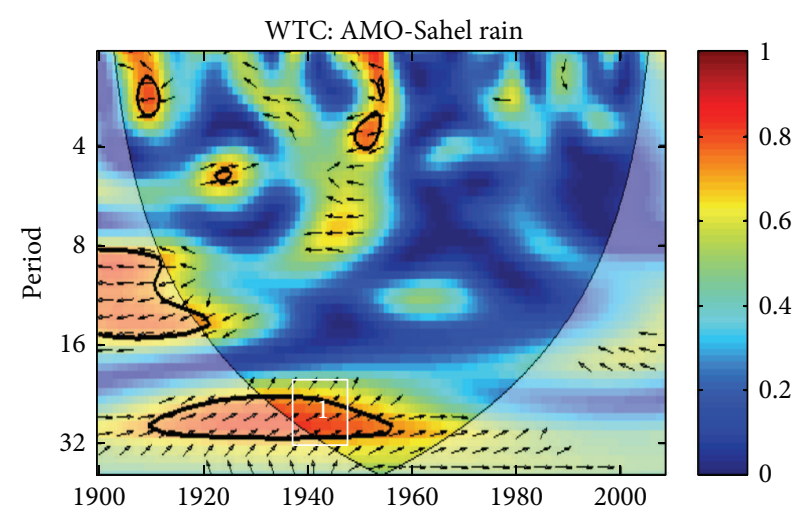

(d)

FIgure 3: Cross wavelet spectrum. (a) Nino 3.4, (b) Nino 3.4, (c) Atlantic Multidecadal Oscillation (AMO) and wavelet coherence, and (d) Atlantic Multi-decadal Oscillation (AMO). (In-phase, pointing right; anti-phase, pointing left; and leading by $90^{\circ}$ pointing straight down; see text for details and interpretation). The thick contour enclosed regions are greater than $95 \%$ confidence for a red-noise process. The thin solid line indicates the "cone of influence," where edge effects become important.

year band, 1-4-year band, 1-2-year band, and 2-5-year band for ENSO, NAO, and IOD, respectively. These interannual cycles have time scales of less than 8 years. In addition, the region that is statistically significant at $95 \%$ confidence for IOD is important with reference to drought of 1980s in the region. Also, multidecadal variability of AMO shows regions of statistical significance at 38-32-year period around the early 1900s. The statistically significant periodicity has however gradually decreased from 40 -year to 16 -year cycle in 2000s. The next step is to expand these time series into frequency space by applying CWT as a band filter to the time series. This will help in finding localized periodicities and in feature extraction. Cross wavelet transform will determine if these associations are merely coincidences by obtaining the frequency component of the hydroclimate variability as a function of time. Wavelet transform coherency (WTC) between two CWT will address the statistical significance of the coherences as well as confidence level against noise. In this analysis, we applied the $95 \%$ confidence level.

4.2. Cross Wavelet Transform and Wavelet Coherence. The XWT and WTC between rainfall and the four climate indices are shown in Figures 3 and 4. According to Torrence and Compo [57], XWT is a representation of cross correlation between rainfall and each climate index as a function of time and frequency. The phase difference between the climate indices and precipitation is represented by the vectors while the locally significant power of the red-noise spectrum at significance level of $\alpha=0.1$ is shown by the bold solid contour line [57]. The lighter black contour line is the cone of influence (COI), where edge effects are not negligible. The coherence power between two series is shown in the color code, red to blue (strong to weak).

ENSO's role in modulating Sahel precipitation shows high common power (good correlation) at 3 bands, (1) 1-2year band localized around 1970, (2) 3-4-year band localized between 1983 and 1986, and (3) 4-6-year band localized between 1990 and 2000 years (Figure 3(a)). According to Grinsted [58], cause and effect relationship in XWT is indicated by phase lock oscillation. The 3-4-year band is pointing left (antiphase) indicating a cause and effect relationship between the drought of 1983 and 1982/83 El Niño episode. The coherency between precipitation and ENSO (Figure 3(b)) also shows three high common powers that are 


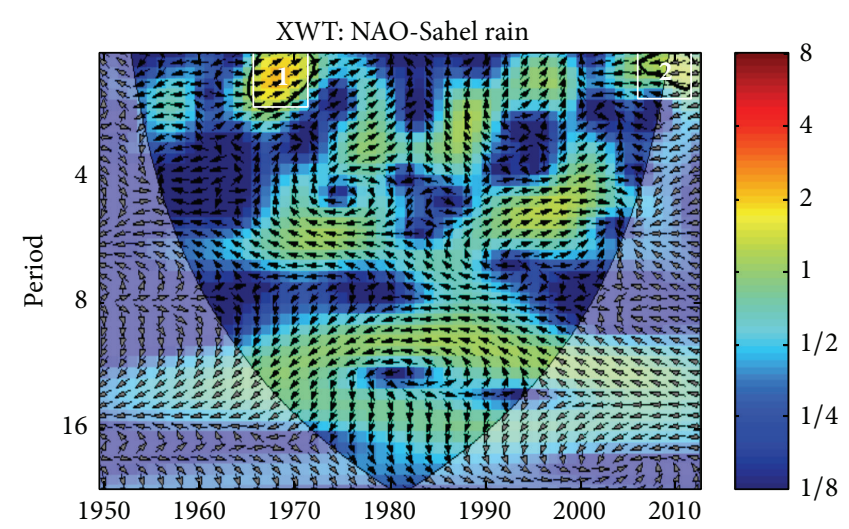

(a)

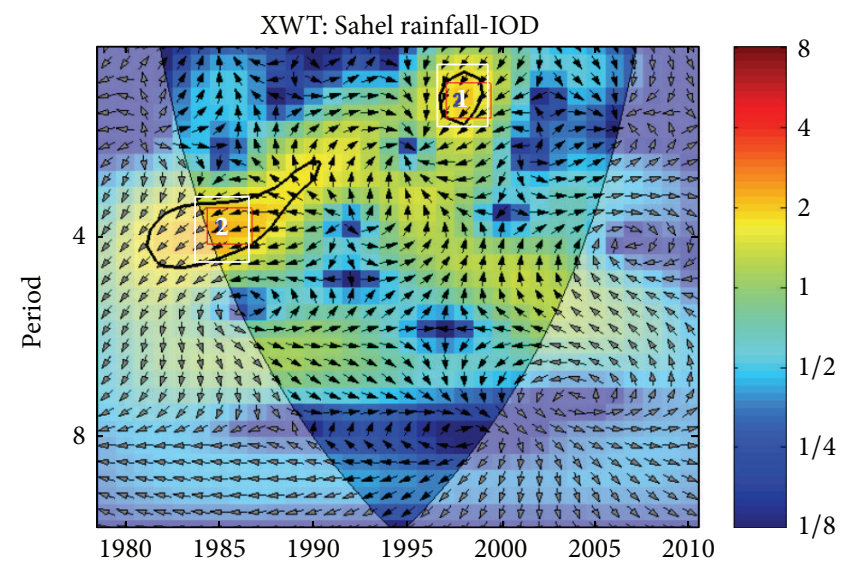

(c)

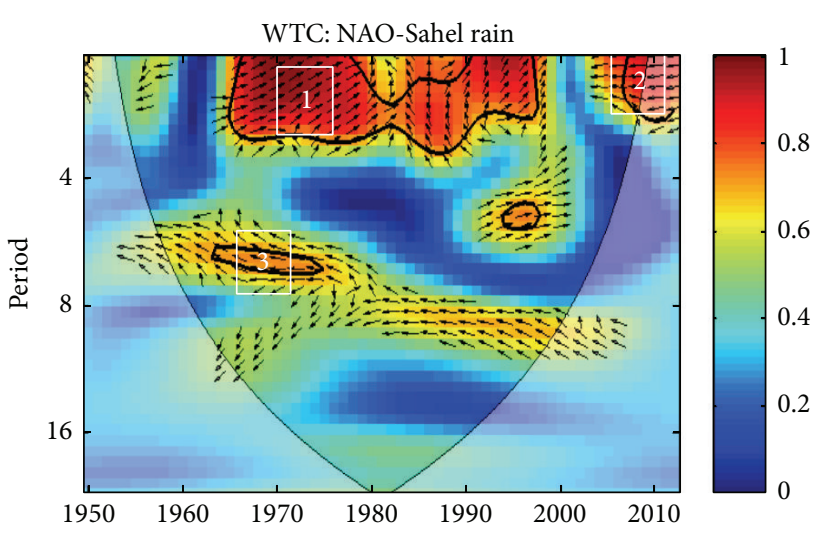

(b)

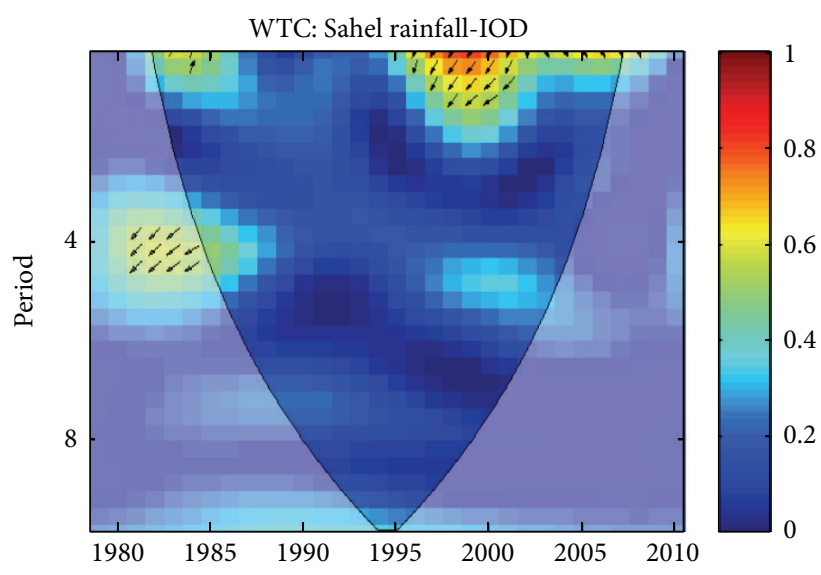

(d)

FIgUre 4: The same as Figure 3 but for (a-b) North Atlantic Oscillation and (c-d) Indian Ocean Dipole.

statistically significant, (1) 1-2-year band localized around 2000, (2) 4-6-year band localized between 1990 and 2000, and (3) 9-10-year band localized between 1965 and early 1970s. The spectral coherency in the 4-6-year band is very strong and noteworthy since it coincides with the onset of rain recovery in the Sahel region [59]. However, because the oscillation is not phase-locked, we can only speculate that there is statistically significant association between the increasing rainfall and Nino 3.4. ENSO, according to Ward [60], influenced high frequency rainfall variability in Sahel while [32] linked strong ENSO events teleconnection to Sahel precipitation to developing and decaying phase of El Niño and La Niña, respectively.

In the XWT between rainfall and AMO shown in Figure 3(c), notice the statistically significant cross wavelet power and consistent phase angle stretching from early $1920 \mathrm{~s}$ to 2000 which is associated with signal in the 25-38-year band. Many studies have shown that precipitation in the Sahel region of Africa is influenced by oceanic conditions impact on atmospheric circulations especially Atlantic Multidecadal Oscillation AMO [23] and El Niño-Southern Oscillation ENSO [16]. The coherency spectra that are significant at the 25-32-year band from late 1910s to late 1950s correspond to the years of positive rainfall anomalies shown in Figure 1(a). This is significant in relation to the reported increase in precipitation associated with warm phase of AMO [24, 25]. Wavelet transform coherence analysis also revealed a relatively antiphase relationship between AMO and precipitation signifying cause and effect.

As seen in Figure 4(a), there is a strong agreement between NAO and Sahel rainfall indicated in the XWT between 1- and 2-year band around late 1970 and late 2000s. While the second band (2) is phase-locked, the first band (1) however indicates a nonlinear relationship between ANO and Sahel precipitation. A corresponding strong coherency between NAO and precipitation is evident in the 1-2-year band of late 2000s (Figure 4(b)). In addition, NAO shows a significant spectral coherence with Sahel rainfall between 1and 3-year band localized from 1960 to 2000 (Figure 4(b)). The phase angle is however chaotic. There is antiphase relationship between IOD and GPCP precipitation for period of 3-4 years around 1983-1990 (Figure 4(c)). There is also a significant cross wavelet power for the period of 1997-1998 associated with 2-year band (Figure 4(d)). However, there is no significant coherency between rainfall and IOD for most of the years within COI. The power is also very weak, except for the 1-year band around 1995 to 1998.

These results confirm the conclusions by [34] and Nicholson [19] that the interannual to decadal variability in precipitation over in this region is not controlled by any 
dominant mechanism. The 1983-1987 years corresponding to the drought of the late 1970s to late 1980s have been described as intense [19]. While Bader and Latif [33] attributed the 1983 drought to Indian Ocean SSTs, our results show that AMO, ENSO, NAO, and IOD all have some correlation with precipitation around the same year though on different bands. There is however strong coherency with ENSO, AMO, and NAO unlike IOD. This suggests that, contrary to [33], AMO, NAO, and ENSO may have influenced events during those drought years [26].

4.3. East versus West Sahel. In this section, we compared the influence of the climatic indices on rainfall variability in east and west Sahel as defined in our data preparation section. The XWT and coherence plots of GPCP rainfall in west and east Sahel for two selected climate indices (ENSO and IOD) with significant difference are shown in Figure 5. As seen in Figures 5(a) and 5(c), there are some significant differences in ENSO association with rainfall variability in eastern and western Sahel. ENSO relationship with precipitation in the east (Figure 5(c)) stretches over longer period and years while showing more variability compared to rainfall-ENSO relationship in western Sahel (Figure 5(a)).

ENSO teleconnection with precipitation in the east shows coherency that is localized from 1990 to 2004 (Figure 5(d)). The coherency for western Sahel is however only localized from 1995 to 2004 (Figure 5(b)). We can thus argue that ENSO teleconnection effect on precipitation is stronger in east Sahel, which is in agreement with [33] who had suggested that ENSO effect on rainfall variability is limited to eastern Sahel.

The results also show some evidence of difference in climatic control of precipitation in west and east Sahel. From Figures 5(e) and 5(g), it appears that IOD control on rainfall variability in Sahel is limited to the east. The XWT for IODrainfall in the east shows 2 regions with statistically significant correlation: (1) in the 2-4-year band localized between late 1980s and early 1990s (Figure 5(g)) and (2) in the 5-6-year band localized between 1986 and 1990. In the west however there is relatively small band with statistically significant correlation around the same band (Figure 5(e)). The spectral coherency plots show a very weak association except a thin spectrum at the 1-year band in the early 2000s (Figures 5(f) and $5(\mathrm{~h}))$. The coherency plot for east Sahel on the other hand has a similar pattern of the weak band as the west. In addition, there is a relatively strong power in the 3-4-year band in the early 1990 (Figure 5(g)), though none of these coherencies are statistically significant.

\section{Summary and Discussion}

With the establishment of a statistical connection between these climate indices and Sahel precipitation, we will next discuss the dynamical mechanism of the connection. The physical mechanisms influencing the multidecadal variability in the Sahel region have been linked to AMO $[24,25]$ while the interannual variability at different time scales are linked to ENSO [30], IOD [33], and NAO [61]. The warm (cold) phase of AMO is associated with enhancement (weakening) of Sahel precipitation [24]. The increased precipitation during the warm phase has been attributed to increased African easterly wave activity and northward displacement of Intertropical Convergence Zone (ITCZ) [62]. On the other hand, El Niño/La Niña Southern Oscillation (ENSO/LNSO) [63], a coupled cycle of atmosphere and ocean [64], has been linked to the devastating droughts of 1970s and 1980s in the Sahel of Africa [15]. Also, Okonkwo et al. [65] characterized the relationship between West African jet streams and ENSO and found enhanced variability of African Easterly Jet (AEJ), Tropical Easterly Jet (TEJ), and low-level African Westerly Jet (AWJ) which are coupled with (ENSO/LNSO). Further analysis by [65] suggests a statistically significant association between TEJ and the El Niño events of the 1980s that led to intense drought in the Sahel region of West Africa. El Nino results in the weakening of West African Monsoon (WAM) flow, creating a dry condition across the Sahel region [66]. La Niña on the other hand creates a wet condition through the enhancement of Walker circulation [59].

This advanced review had focused on identifying and illuminating the nature of interannual and decadal to multidecadal variability of precipitation in Sahel region. It should however be pointed out that the Sahelian climate under future climate warming is still complex and controlled by one dominant ocean dynamics. The analysis is however a useful tool in identifying the major climate index with a robust relationship with Sahel precipitation (drought) variability on annual to interannual timescale.

The findings are summarized as follows.

(1) ENSO, NAO, AMO, and IOD all have strong relationship with precipitation at periodicity.

(2) There is an antiphase relationship between Sahel precipitation and ENSO, the 3-4-year band localized around 1982/83 El Niño episode.

(3) This indicates a cause and effect relationship between the droughts of 1983 and 1982/83 El Niño.

(4) The interrelationship between ENSO composite of 1983-1987, cold phase of AMO, and warm phase of NAO explained the drought of the early 1980 s.

While this advanced review does not resolve all the outstanding issues on rainfall variability in Sahel region, it however points to some climate indices that have significant control to current improvement in precipitation as well as the most recent severe drought in the region. This improved knowledge is a first step in better planning and management of water resources in Sahel region. One limitation of the study is that it is based on the different time scales for different climate indices considered. This study however has provided some key aspects of SST forcing on rainfall variability across the Sahel Region. Advancing this understanding of variability in rainfall and climate forcing could therefore improve the accuracy of rainfall forecast. 


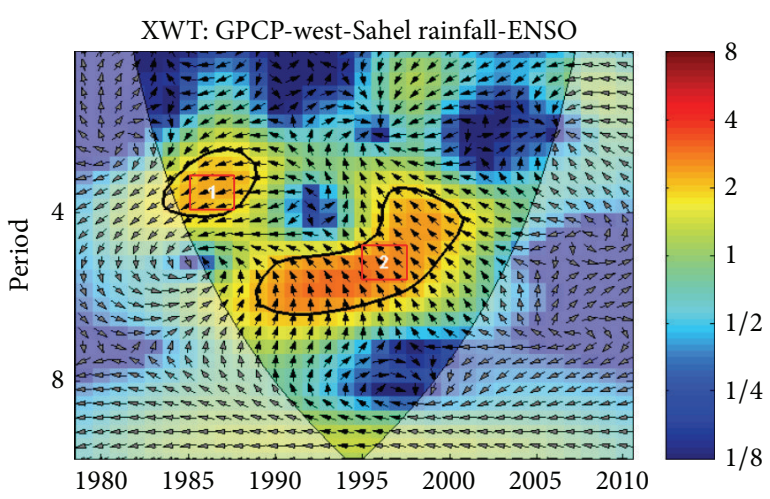

(a)

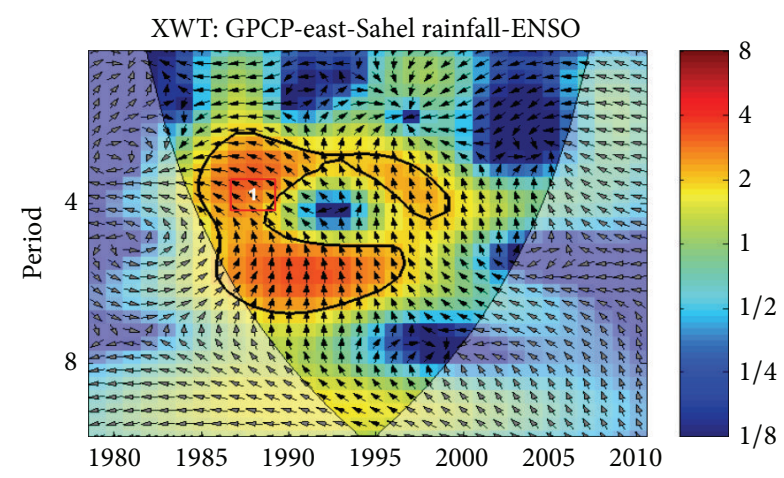

(c)

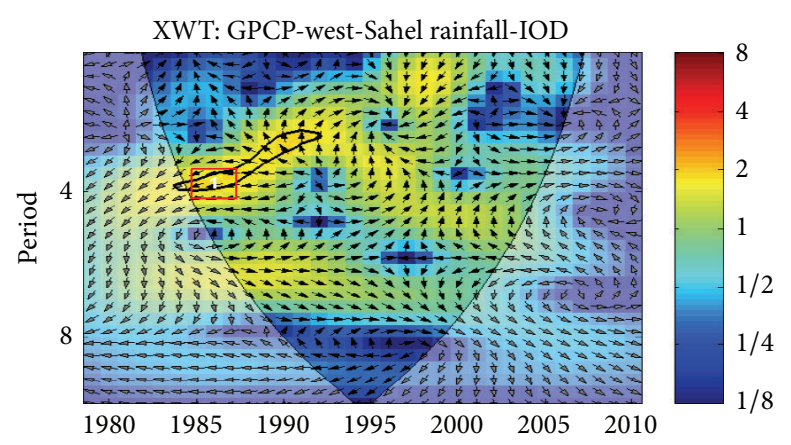

(e)

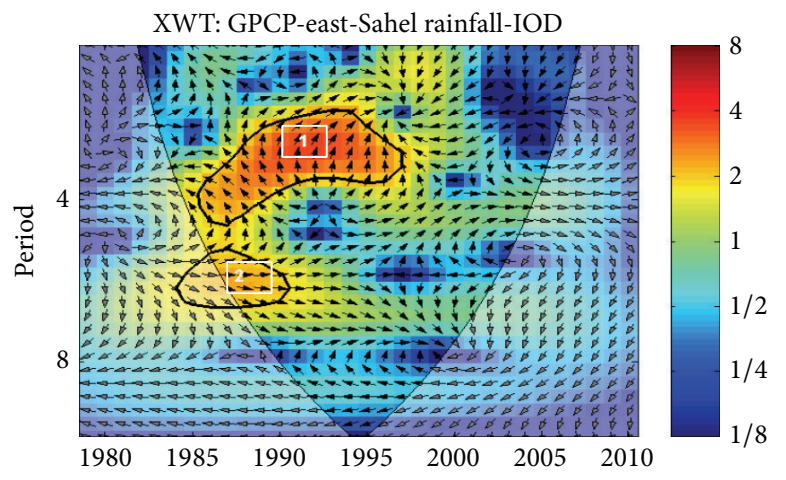

(g)

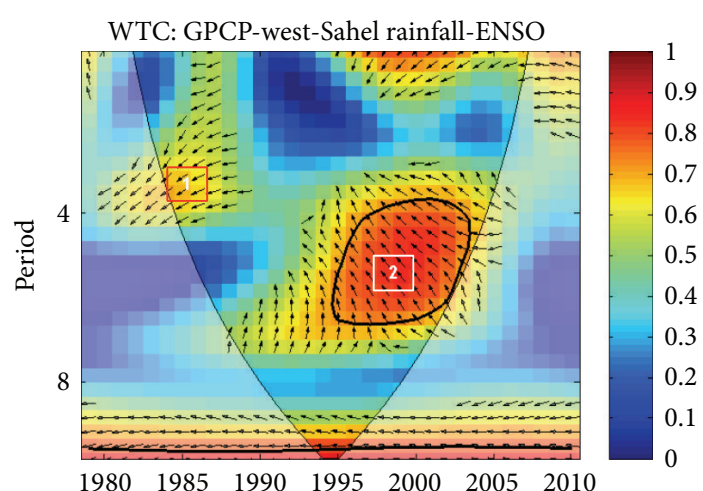

(b)

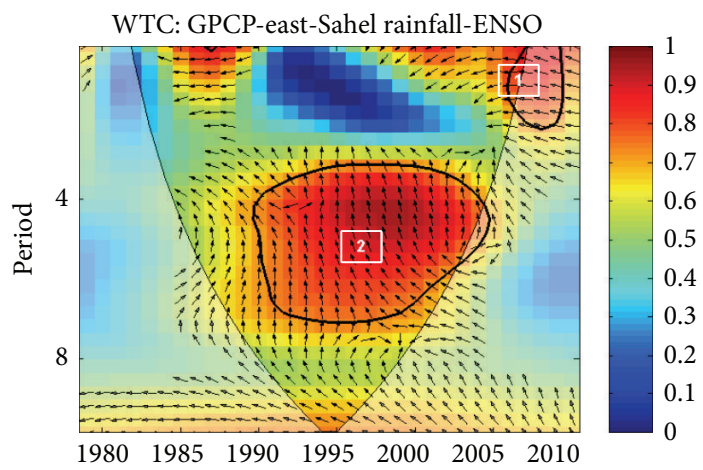

(d)

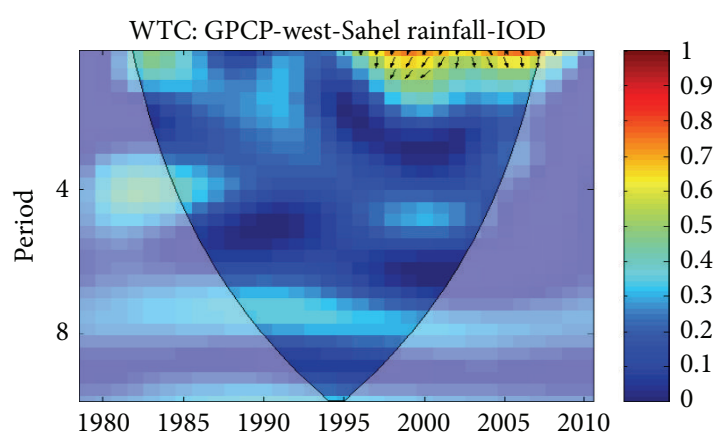

(f)

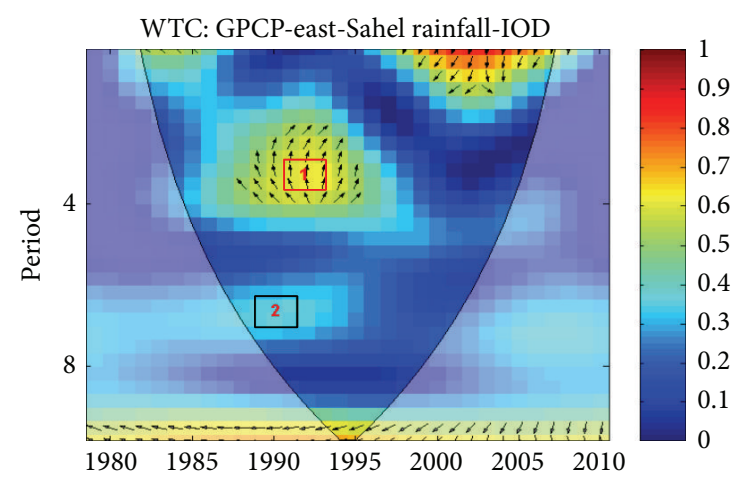

(h)

FIGURE 5: Cross wavelet spectrum (left) and wavelet coherence (right) between GPCP Sahel precipitation (east and west) and selected climate indices (ENSO and IOD). (a)-(b) Western Sahel rainfall and ENSO, (c)-(d) eastern Sahel Rainfall and ENSO, (e)-(f) western Sahel rainfall and IOD, and (g)-(h) eastern Sahel rainfall and IOD. In-phase, pointing right; anti-phase, pointing left; and leading by $90^{\circ}$ pointing straight down; (see text for details and interpretation). The thick contour enclosed regions are greater than 95\% confidence for a red-noise process. The thin solid line indicates the "cone of influence," where edge effects become important. 


\section{Conflict of Interests}

The author declares that there is no conflict of interests regarding the publication of this paper.

\section{Acknowledgments}

The author would like to acknowledge the support of Beltsville Center for Climate Systems Observations (BCCSO) and the National Oceanic and Atmospheric Administration (NOAA) Center for Atmospheric Sciences (NCAS) both at Howard University.

\section{References}

[1] Z. T. Segele and P. J. Lamb, "Characterization and variability of Kiremt rainy season over Ethiopia," Meteorology and Atmospheric Physics, vol. 89, no. 1-4, pp. 153-180, 2005.

[2] C. Cook, C. J. C. Reason, and B. C. Hewitson, "Wet and dry spells within particularly wet and dry summers in the South African summer rainfall region," Climate Research, vol. 26, no. 1, pp. 17-31, 2004.

[3] S. E. Nicholson, "On the factors modulating the intensity of the tropical rainbelt over West Africa," International Journal of Climatology, vol. 29, no. 5, pp. 673-689, 2009.

[4] P. Desanker and C. Magadza, Africa Climate Change 2001: Impacts, Adaptation and Vulnerability, Cambridge University Press, New York, NY, USA, J. J. McCarthy, O. F. Canziani, N. A. Leary, D. J. Dokken, K. S. White, Eds., 2001.

[5] R. Washington, M. Harrison, D. Conway et al., "African climate change: taking the shorter route," Bulletin of the American Meteorological Society, vol. 87, no. 10, pp. 1355-1366, 2006.

[6] S. E. Nicholson, C. J. Tucker, and M. B. Ba, "Desertification, drought, and surface vegetation: an example from the West African Sahel," Bulletin of the American Meteorological Society, vol. 79, no. 5, pp. 815-829, 1998.

[7] A. Tarhule and P. J. Lamb, "Climate research and seasonal forecasting for West Africans," Bulletin of the American Meteorological Society, vol. 84, no. 12, pp. 1741-1759, 2003.

[8] Disaster Management Centre D. M. C., Natural Disasters: Causes and Effects. Lesson 7: Drought, Disaster Management Centre, University of Wisconsin, Madison, Wis, USA, 1995.

[9] J. G. Charney, "Dynamics of deserts and drought in the Sahel," Quarterly Journal of the Royal Meteorological Society, vol. 101, no. 428, pp. 193-202, 1975.

[10] Y. Xue and J. Shukla, “The influence of land surface properties on Sahel climate-part I: desertification," Journal of Climate, vol. 6, no. 12, pp. 2232-2245, 1993.

[11] C. M. Taylor, E. F. Lambin, N. Stephenne, R. J. Harding, and R. L. $\mathrm{H}$. Essery, "The influence of land use change on climate in the Sahel," Journal of Climate, vol. 15, no. 24, pp. 3615-3629, 2002.

[12] K. Y. Li, M. T. Coe, N. Ramankutty, and R. D. Jong, "Modeling the hydrological impact of land-use change in West Africa," Journal of Hydrology, vol. 337, no. 3-4, pp. 258-268, 2007.

[13] J. F. Reynolds and S. D. M. Stafford, Global Desertification: Do Humans Cause Deserts? Dahlem University Press, Berlin, Germany, 2002.

[14] S. D. Prince, Spatial and Temporal Scales For Detection of Desertification in Global Desertification: Do Humans Cause Deserts?
Dahlem University Press, Berlin, Germany, J. F. Reynolds, D. M. S. Smith, Eds., 2002.

[15] A. Giannini, R. Saravanan, and P. Chang, "Oceanic forcing of Sahel rainfall on interannual to interdecadal time scales," Science, vol. 302, no. 5647, pp. 1027-1030, 2003.

[16] C. Caminade and L. Terray, "Twentieth century Sahel rainfall variability as simulated by the ARPEGE AGCM, and future changes," Climate Dynamics, vol. 35, no. 1, pp. 75-94, 2010.

[17] M. Biasutti, I. M. Held, A. H. Sobel, and A. Giannini, "SST forcings and Sahel rainfall variability in simulations of the twentieth and twenty-first centuries," Journal of Climate, vol. 21, no. 14, pp. 3471-3486, 2008.

[18] A. Giannini, M. Biasutti, I. M. Held, and A. H. Sobel, "A global perspective on African climate," Climatic Change, vol. 90, no. 4, pp. 359-383, 2008.

[19] S. E. Nicholson, "The West African Sahel: a review of recent studies on the rainfall regime and its interannual variability," ISRN Meteorology, vol. 2013, Article ID 453521, 32 pages, 2013.

[20] C. K. Folland, T. N. Palmer, and D. E. Parker, "Sahel rainfall and worldwide sea temperatures, 1901-85," Nature, vol. 320, no. 6063, pp. 602-607, 1986.

[21] J. Lu and T. L. Delworth, "Oceanic forcing of the late 20th century Sahel drought," Geophysical Research Letters, vol. 32, no. 22, Article ID L22706, pp. 1-5, 2005.

[22] M. Hoerling, J. Hurrell, J. Eischeid, and A. Phillips, "Detection and attribution of twentieth-century northern and southern African rainfall change," Journal of Climate, vol. 19, no. 16, pp. 3989-4008, 2006.

[23] I. Polo, A. Ullmann, P. Roucou, and B. Fontaine, "Weather regimes in the Euro-Atlantic and Mediterranean sector, and relationship with West African rainfall over the 1989-2008 period from a self-organizing maps approach," Journal of Climate, vol. 24, no. 13, pp. 3423-3432, 2011.

[24] R. Zhang and T. L. Delworth, "Impact of Atlantic multidecadal oscillations on India/Sahel rainfall and Atlantic hurricanes," Geophysical Research Letters, vol. 33, no. 17, Article ID L17712, 2006.

[25] T. Delworth, L. R. Zhang, and M. E. Mann, "Decadal to centennial variability of the Atlantic from observations and models. Ocean circulation: mechanisms and impacts," Geophysical Monograph Series, vol. 173, pp. 121-148, 2007.

[26] I. Polo, B. Rodríguez-Fonseca, T. Losada, and J. García-Serrano, "Tropical atlantic variability modes (1979-2002) - part I: timeevolving SST modes related to West African rainfall," Journal of Climate, vol. 21, no. 24, pp. 6457-6475, 2008.

[27] F. Raicich, N. Pinardi, and A. Navarra, "Teleconnections between Indian monsoon and Sahel rainfall and the Mediterranean," International Journal of Climatology, vol. 23, no. 2, pp. 173186, 2003.

[28] C. E. Chung and V. Ramanathan, "Weakening of north Indian SST gradients and the monsoon rainfall in India and the Sahel," Journal of Climate, vol. 19, no. 10, pp. 2036-2045, 2006.

[29] D. P. Rowell, "Teleconnections between the tropical Pacific and the Sahel," Quarterly Journal of the Royal Meteorological Society, vol. 127, no. 575, pp. 1683-1706, 2001.

[30] M. Joly, A. Voldoire, H. Douville, P. Terray, and J.-F. Royer, "African monsoon teleconnections with tropical SSTs: validation and evolution in a set of IPCC4 simulations," Climate Dynamics, vol. 29, no. 1, pp. 1-20, 2007. 
[31] S. Janicot and B. Sultan, "Intra-seasonal modulation of convection in the West African monsoon," Geophysical Research Letters, vol. 28, no. 3, pp. 523-526, 2001.

[32] M. Joly and A. Voldoire, "Role of the Gulf of Guinea in the interannual variability of the West African monsoon: what do we learn from CMIP3 coupled simulations?" International Journal of Climatology, vol. 30, no. 12, pp. 1843-1856, 2010.

[33] J. Bader and M. Latif, "The impact of decadal-scale Indian ocean sea surface temperature anomalies on Sahelian rainfall and the North Atlantic oscillation," Geophysical Research Letters, vol. 30, no. 22, pp. 2169-2173, 2003.

[34] L. M. Druyan, "Studies of 21st-century precipitation trends over West Africa," International Journal of Climatology, vol. 31, no. 10, pp. 1415-1424, 2011.

[35] S.-Y. Wang and R. R. Gillies, "Observed change in Sahel rainfall, circulations, African easterly waves, and Atlantic hurricanes since 1979," International Journal of Geophysics, vol. 2011, Article ID 259529, 14 pages, 2011.

[36] J. H. Christensen, T. R. Carter, M. Rummukainen, and G. Amanatidis, "Evaluating the performance and utility of regional climate models: the PRUDENCE project," Climatic Change, vol. 81, no. 1, pp. 1-6, 2007.

[37] G. S. Jenkins, A. T. Gaye, and B. Sylla, "Late 20th century attribution of drying trends in the Sahel from the Regional Climate Model (RegCM3)," Geophysical Research Letters, vol. 32, no. 22, Article ID L22705, pp. 1-4, 2005.

[38] G. Wang and E. A. B. Eltahir, "Ecosystem dynamics and the Sahel drought," Geophysical Research Letters, vol. 27, no. 6, pp. 795-798, 2000.

[39] B. Cazelles, M. Chavez, D. Berteaux et al., "Wavelet analysis of ecological time series," Oecologia, vol. 156, no. 2, pp. 287-304, 2008.

[40] M. À. Rodríguez-Arias and X. Rodó, "A primer on the study of transitory dynamics in ecological series using the scale-dependent correlation analysis," Oecologia, vol. 138, no. 4, pp. 485504, 2004.

[41] R. F. Adler, G. J. Huffman, A. Chang et al., “The version-2 global precipitation climatology project (GPCP) monthly precipitation analysis (1979-present)," Journal of Hydrometeorology, vol. 4, no. 6, pp. 1147-1167, 2003.

[42] J. E. Janowiak, "An investigation of interannual rainfall variability in Africa," Journal of Climate, vol. 1, no. 3, pp. 240-255, 1988.

[43] A. Kaplan, M. A. Cane, Y. Kushnir, A. C. Clement, M. B. Blumenthal, and B. Rajagopalan, "Analyses of global sea surface temperature 1856-1991," Journal of Geophysical Research C: Oceans, vol. 103, no. 9, pp. 18567-18589, 1998.

[44] Climate Prediction Center (CPC), "Description of changes to oceanic Niño indexes," 2013, http://www.cpc.ncep.noaa.gov/ products/analysis_monitoring/ensostuff/ONI_change.shtml.

[45] N. H. Saji, B. N. Goswami, P. N. Vinayachandran, and T. Yamagata, "A dipole mode in the tropical Indian ocean," Nature, vol. 401, no. 6751, pp. 360-363, 1999.

[46] J. W. Hurrell, "Decadal trends in the North Atlantic oscillation: regional temperatures and precipitation," Science, vol. 269, no. 5224, pp. 676-679, 1995.

[47] P. D. Jones, T. Jonsson, and D. Wheeler, "Extension to the North Atlantic oscillation using early instrumental pressure observations from gibraltar and south-west Iceland," International Journal of Climatology, vol. 17, no. 13, pp. 1433-1450, 1997.
[48] J. C. Rogers, “The association between the North Atlantic oscillation and the Southern oscillation in the Northern Hemisphere," Monthly Weather Review, vol. 112, no. 10, pp. 1999-2015, 1984.

[49] UCAR, Persistent Patterns That Shape Weather and Climate Variability: A Glossary, NCAR \& UCAR, Boulder, Colo, USA, 2009, B. H. K.Trenberth, Z. Gallon, Eds.

[50] M. E. Brown, K. de Beurs, and A. Vrieling, "The response of African land surface phenology to large scale climate oscillations," Remote Sensing of Environment, vol. 114, no. 10, pp. 22862296, 2010.

[51] G. J. Huffman, R. F. Adler, M. M. Morrissey et al., "Global precipitation at one-degree daily resolution from multisatellite observations," Journal of Hydrometeorology, vol. 2, no. 1, pp. 36-50, 2001.

[52] S. Nicholson, "On the question of the "recovery" of the rains in the West African Sahel," Journal of Arid Environments, vol. 63, no. 3, pp. 615-641, 2005.

[53] P. J. Lamb, "Sub-Saharan rainfall update for 1982: continued drought," Journal of Climatology, vol. 3, no. 4, pp. 419-422, 1983.

[54] P. J. Lamb and R. A. Peppler, "Further case studies of tropical Atlantic surface atmospheric and oceanic patterns associated with sub-Saharan drought," Journal of Climate, vol. 5, no. 5, pp. 476-488, 1992.

[55] T. Lebel and A. Ali, "Recent trends in the Central and Western Sahel rainfall regime (1990-2007)," Journal of Hydrology, vol. 375, no. 1-2, pp. 52-64, 2009.

[56] F. Sima, A. Kamga, I. Raiva, F. S. Dekaa, and A. I. James, "State of the climate 2012: [Africa] West Africa," Bulletin of the American Meteorological Society, vol. 94, no. 8, pp. S161-S166, 2013.

[57] C. G. Torrence and P. Compo, "A practical guide to wavelet analysis," Bulletin of the American Meteorological Society, vol. 79, no. 1, pp. 61-78, 1998.

[58] A. Grinsted, J. C. Moore, and S. Jevrejeva, "Application of the cross wavelet transform and wavelet coherence to geophysical times series," Nonlinear Processes in Geophysics, vol. 11, no. 5-6, pp. 561-566, 2004.

[59] S. E. Nicholson, B. Some, and B. Kone, "An analysis of recent rainfall conditions in West Africa, including the rainy seasons of the 1997 El Nino and the 1998 La Nina years," Journal of Climate, vol. 13, no. 14, pp. 2628-2640, 2000.

[60] M. N. Ward, "Diagnosis and short-lead time prediction of summer rainfall in tropical North Africa at interannual and multidecadal timescales," Journal of Climate, vol. 11, no. 12, pp. 31673191, 1998.

[61] C. K. Folland, J. Knight, H. W. Linderholm, D. Fereday, S. Ineson, and J. W. Hurrel, "The summer North Atlantic oscillation: past, present, and future," Journal of Climate, vol. 22, no. 5, pp. 1082-1103, 2009.

[62] E. R. Martin and C. D. Thorncroft, "The impact of the AMO on the West African monsoon annual cycle," Quarterly Journal of the Royal Meteorological Society, vol. 140, no. 678, pp. 31-46, 2014.

[63] K. E. Trenberth and D. P. Stepaniak, "Indices of El Niño evolution,” Journal of Climate, vol. 14, no. 8, pp. 1697-1701, 2001.

[64] J. Bjerknes, "Atmospheric teleconnections from the equatorial Pacific," Monthly Weather Review, vol. 97, no. 3, pp. 163-172, 1969.

[65] C. Okonkwo, B. Demoz, and S. Tesfai, "Characterization of West African jet streams and their association to ENSO events and 
rainfall in ERA-interim 1979-2011," Advances in Meteorology, vol. 2014, Article ID 405617, 12 pages, 2014.

[66] S. Janicot, F. Mounier, S. Gervois, B. Sultan, and G. N. Kiladis, "The dynamics of the West African monsoon-part V: the detection and role of the dominant modes of convectively coupled equatorial Rossby waves," Journal of Climate, vol. 23, no. 14, pp. 4005-4024, 2010. 

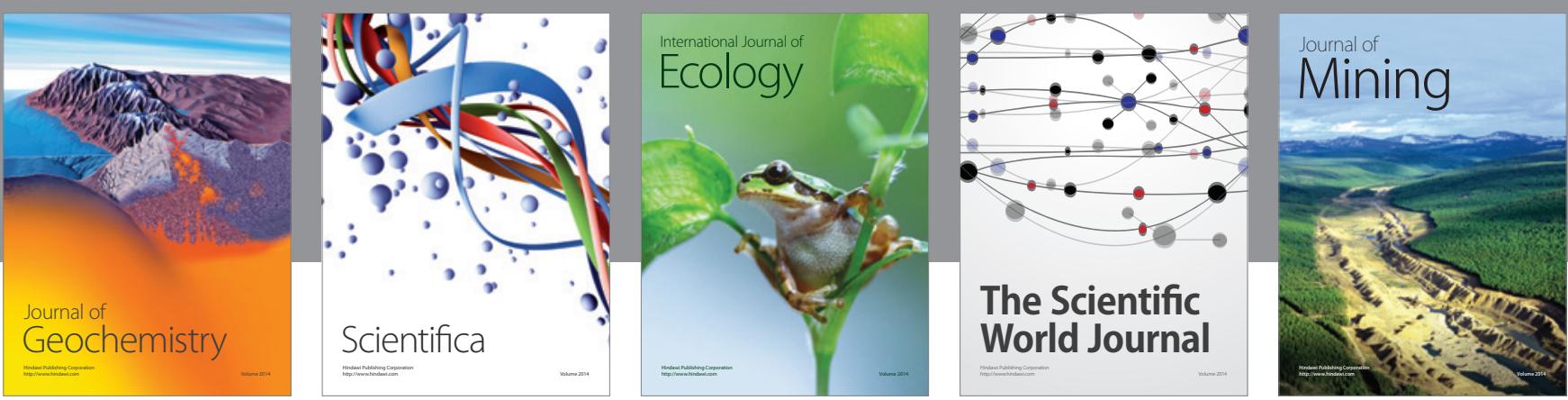

The Scientific World Journal
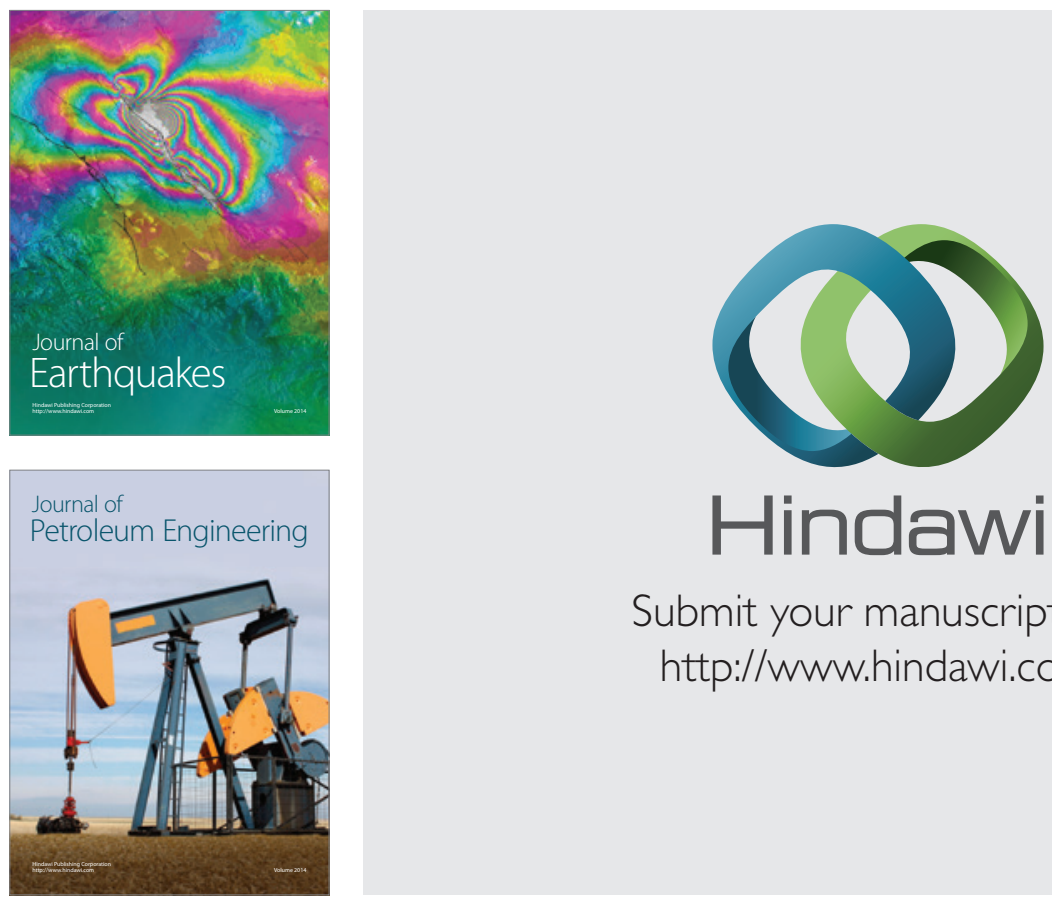

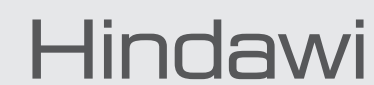

Submit your manuscripts at

http://www.hindawi.com
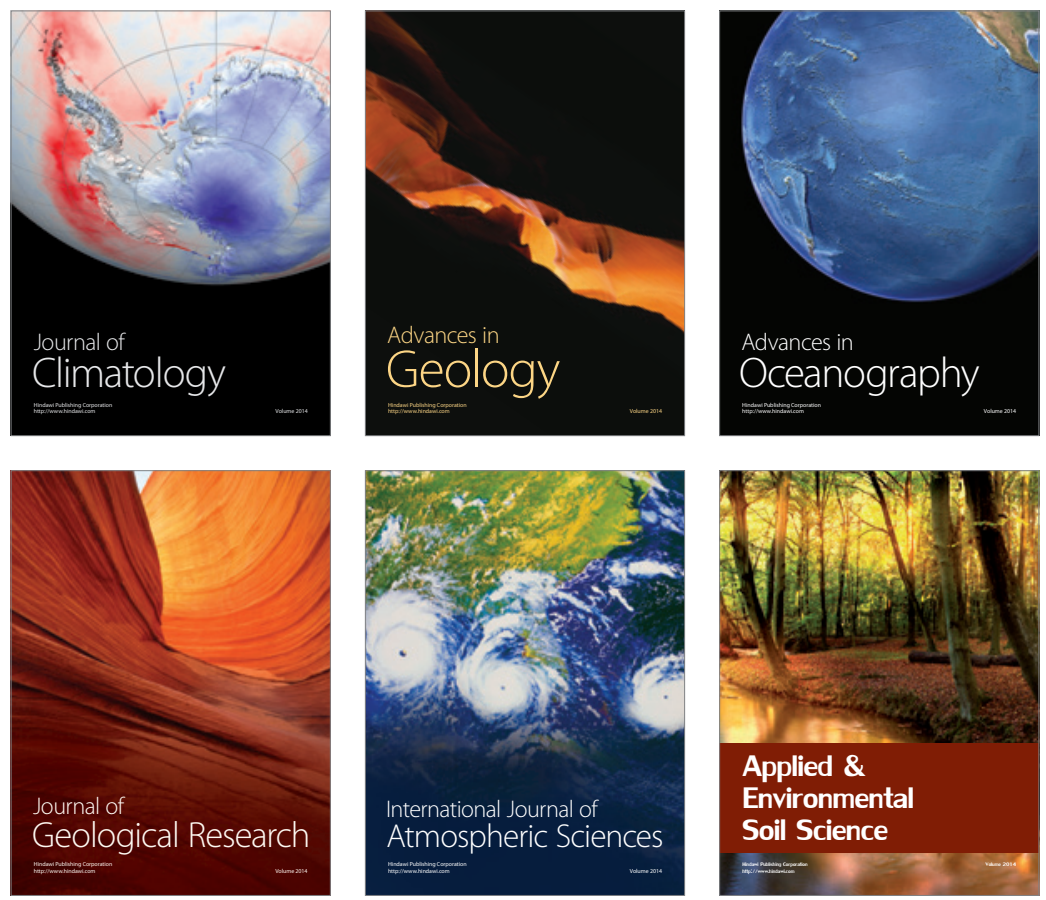
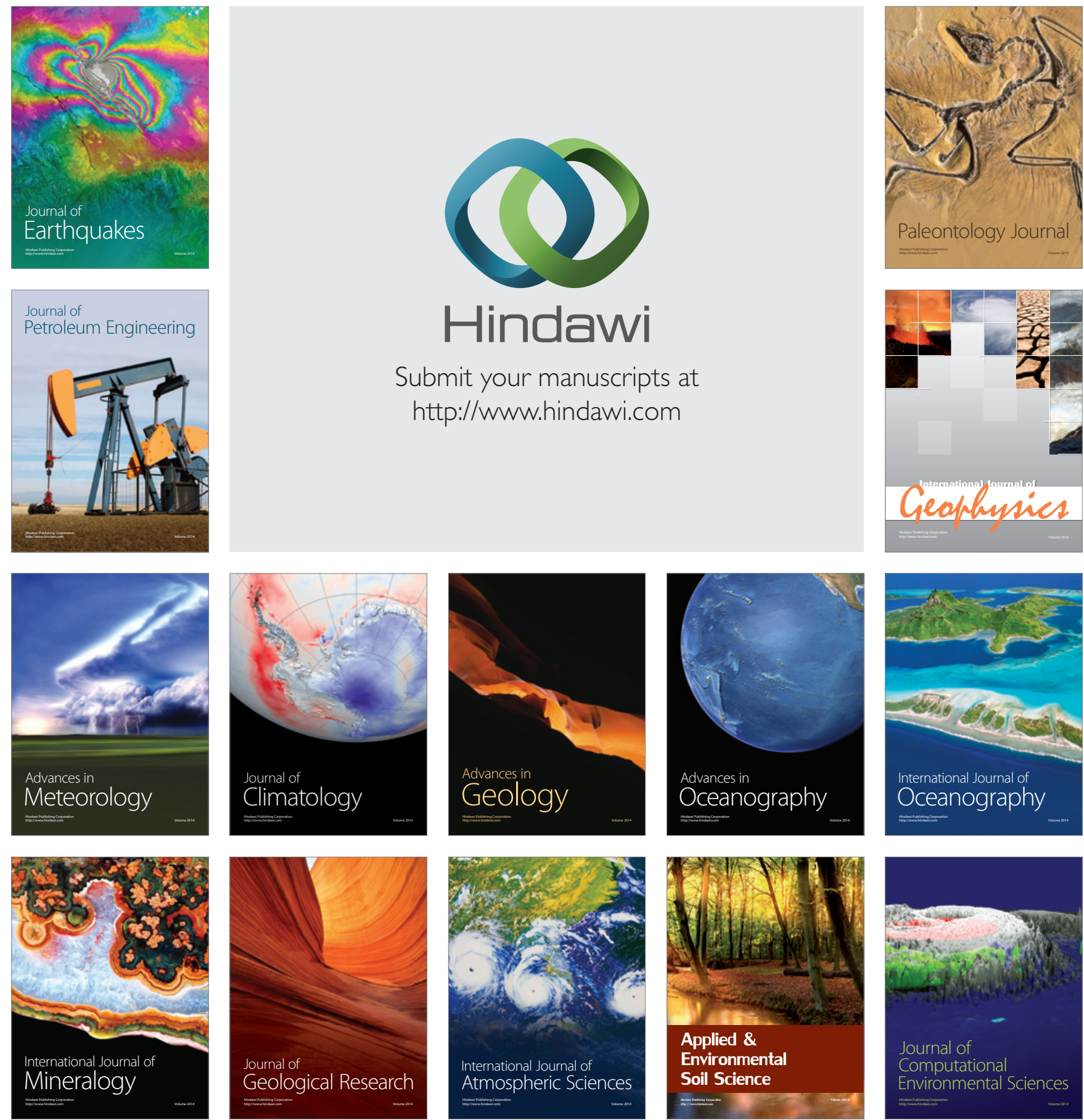